\title{
LESSON 113
}

Statements of account

Statements of account show the trading position between two firms and are usually sent out once a month by the seller to the buyer to remind the buyer what he owes the seller. The statement provides a check for the two firms in the event of an error on their books.

On a sheet of A5 paper $(210 \times 148 \mathrm{~mm})$ rule up this outline following the instructions given, and use it behind a sheet of Bank typing paper each time you type a statement.

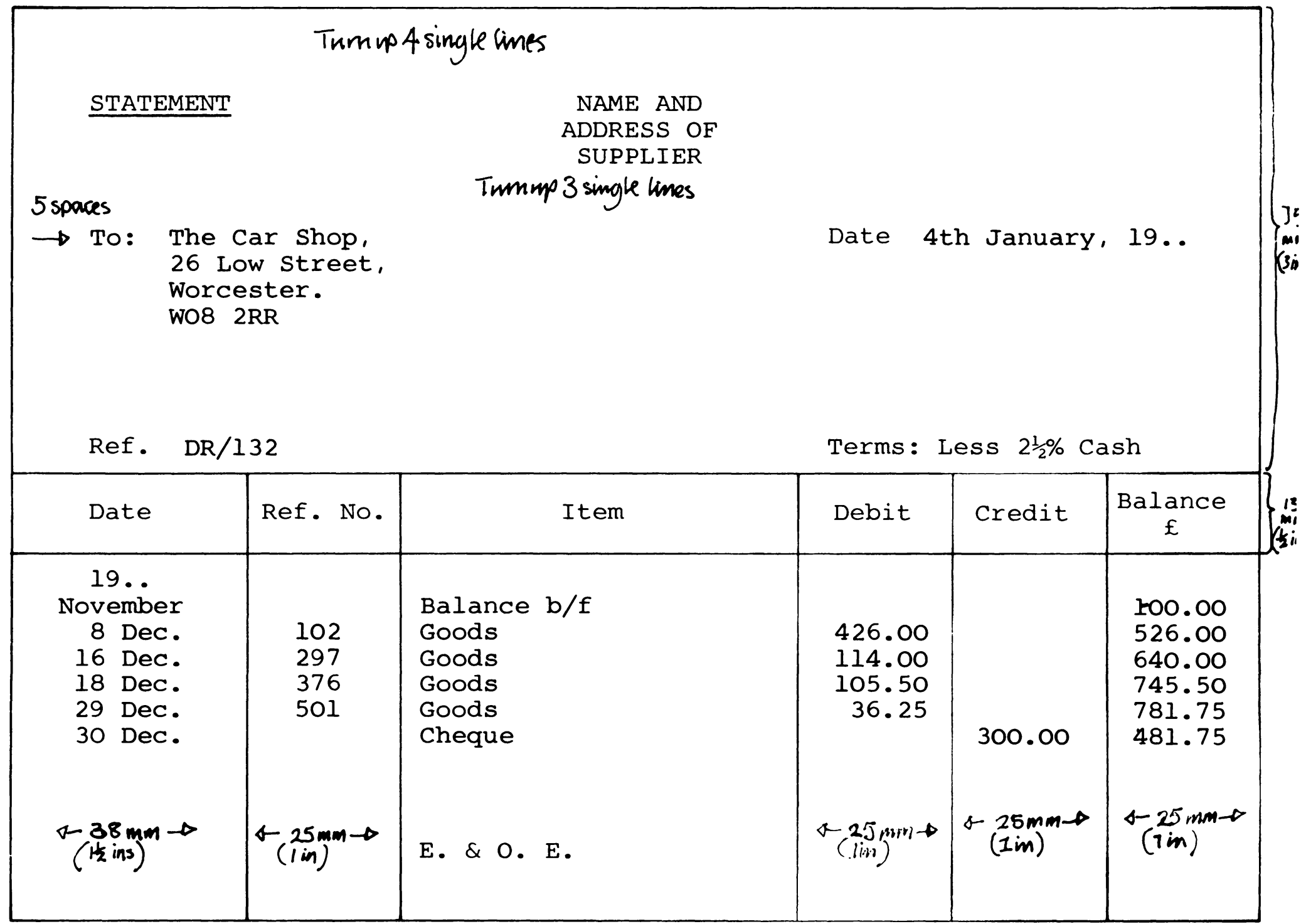

Type in the suggested headings so that you will see them through your top sheet as you type the exercises.

Take your ruled up form out of the machine and use it as a backing sheet as you fill in the information as above on your top sheet of A5 paper $(210 \times 148 \mathrm{~mm})$. You are to type the following name and address over where it says, 'Name and Address of Supplier.' Auto Spares Limited, 14 Luton Road, Northampton. NO2 5EE

Keep your ruled form - you will need it for later exercises.

UNIT 29

LESSON 113 